\title{
ПСИХОЛОГИЧЕСКИЕ ФАКТОРЫ ЭМОЦИОНАЛЬНЫХ СОСТОЯНИЙ, ИМЕЮЩИЕ ОТНОШЕНИЕ К УГОЛОВНОМУ ЗАКОНОДАТЕЛЬСТВУ РЕСПУБЛИКИ УЗБЕКИСТАН
}

\author{
Махмудова Х.T. \\ Республиканский центр судебных экспертиз им. Х.Сулеймановой, \\ Ташкент, Республика Узбекистан
}

В статье рассматривается эмоциональное состояние личностей, совершивших преступления против жизни и здоровья. Анализируются сm. cm. 97, 98 Уголовного кодекса Республики Узбекистан и Постановление Верховного суда Республики Узбекистан, с учетом значимости судебно-психологической экспертизы, при рассмотрении эмоциональных состояний субъектов преступления. Раскрываются состояния стресса и фрустрации при рассмотрении вопросов связанных с совершением преступления против жизни и здоровья, с учетом иных эмоциональных состояний, входящих в раздел преступлений совершенных против личности. Также раскрываются актуальные возможности судебно-психологической экспертизы в решении вопроса о квалификации преступления с учетом законодательств Республики Узбекистан.

Ключевые слова: преступление, личность, эмочия, состояния, физиологический аффрект, стресс, эмоциональное возбуждение, фрустрация.

Как справедливо отметил А.Е. Брусиловский «психология - это стихия, которая окружает суд со всех сторон» [1]. Следует отметить, что суд сталкивается с многообразными сложными ситуациями как в уголовных, так и в гражданских делопроизводствах. Долгие годы со стороны правоохранительных органов предпочтение отдавалось только психиатрическим экспертизам, где в рамках уголовных процессов определялась либо “вменяемость», либо «невменяемость» субъекта, в тоже время в рамках гражданских дел психологические познания вообще не учитывались.

В комментариях к Уголовном кодексу Республики Узбекистан (УК РУз), согласно ст. 98 УК РУз отмечено, что «при решении вопроса о том, совершено ли убийство в состоянии фризиологического афффекта, необходимо назначать комплексную психолого-психиатрическую экспертизу» [2].

Очевидно, диагностирование состояния фризиологического аффректа относится сугубо к компетенции психологических познаний в области судебной психологии. На сегодняшний день судебная психология, включающая различные предметные виды судебно-психологических экспертиз, не имеет прямого назначения, т.е. правового статуса. Психолого-психиатрические экспертизы проводятся в экспертных психиатрических учреждениях, и это определяет преобладающую роль психиатрии над психологической компетентностью, которая большей частью зависит от компетентности психиатрической, т.е. от мнения руководителя экспертного учреждения. Сложившаяся ситуация нуждается в разрешении, поскольку психиатры, определяющие свою преобладающую роль в разрешении вопроса о фризиологическом афрфекте, нарушают

Адрес для корреспонденции: Махмудова Хулкар Тилабовна, кандидат психологических наук, доцент, экспертпсихолог Республиканского центра судебных экспертиз им. Х.Сулеймановой, 100105, Узбекистан, г.Ташкент, ул. Фергана йули, 60, тел: 71-209-11-55, 71-209-01-42, e-mail: sudex@minjust.gov.uz 
демаркационную линию компетентных профрессиональных прав. Следует отметить, что в психиатрической сфрере Министерства здравоохранения Республики Узбекистан отсутствует положение об экспертах-психологах, несмотря на привлечение их к проведению комплексных психолого-психиатрических экспертиз.

В Постановлении Пленума Верховного суда от 24.09.2004 года N 13 «0 судебной практике по делам об умышленном убийстве» на сегодняшний день не определена совокупность специальных правил, регулирующих возможности назначения и характер проведения судебно-психологических экспертиз. Следует отметить, что к каждому виду судебной экспертизы применяются стандартные нормы. И эти нормы законодательно определяются разбирательствами в рамках «человеческого фрактора» (психиатрия или психология) [3].

Согласно вышеотмеченному Постановлению Верховного суда (п. 27) «при назначении наказания за умышленное убийство необходимо учитывать все обстоятельства, при которых оно совершено: вид умысла, мотивы, цель и способ, обстановка и стадия совершения преступления, а также личность виновного, его отношение к содеянному, обстоятельства, смягчающие и отягчающие наказание. Равным образом, должны быть исследованы данные, относящиеся к личности потерпевшего, его взаимоотношениям с подсудимым, а также поведение, предшествующее убийству» [3].

Совокупность признаков, обозначенных для исследования криминальных инцидентов по ст. 97 относится к фракторам психологической природы и поэтому имеет отношение к компетентности судебных психологов. Обстоятельства убийств в особо жестокой форме, а также поведение виновных лиц могут быть настолько противоречивыми и не понятными по логике человеческого общежития, что в этих ситуациях рекомендуется уделять особое внимание изучению подобных инцидентов в психологических категориях.

Также, в рамках вышеупомянутого Постановления Верховного суда, «в случаях совершения виновным действий, предусмотренных в части второй статьи 97 УК РУз проведение стационарной судебно-психиатрической экспертизы обязательно». С учетом накопленного практического опыта судебно-психиатрических освидетельствований испытуемых, совершивших особо тяжкие преступления против жизни и здоровья человека, последние не могут считаться источником объективного вменения человеку ответственности по данной статье. Исходя из отмеченной статистики, возникает резонный вопрос - учитываются ли обстоятельства, отмеченные в Постановлении Пленума Верховного суда от 24.09.2004 г. «вид умысла, мотивы, цель и способ, обстановка и стадии совершения преступления, а также личность виновного, его отношение к содеянному", при психиатрическом освидетельствовании испытуемых совершивших особо тяжкие преступления против жизни и здоровье человека? Совершенно очевидно, что выводы психиатров заключающиеся в позиции «вменяем» - «невменяем», не вносят ясность относительно проблемы, связанной с установлением вида умысла, мотивов, цели и способов, обстановки и стадии совершенного преступления.

Как правило, судебно-психиатрическая экспертиза назначается в том случае, когда возникают сомнения в психической полноценности испытуемых. Судебно-психиатрическая экспертиза в уголовном процессе назначается для определения психического состояния обвиняемого или подозреваемого в случаях, когда имеются сомнения по поводу его вменяемости, либо способности к моменту рассмотрения дела отдавать отчет в своих действиях или руководить ими. В подавляющем большинстве случаев к обязанностям экспертов-психиатров относятся 
диагностика нозологических особенностей и синдромальной патохарактерологии, связанной с выяснением степени выраженности нарушений в структуре психического состояния [4].

В обязанности же эксперта-психолога входят как оценка нормативных вариантов критических возможностей личности, так и оценка компенсаторных способностей и психологических «защит» на фоне установления степени и механизмов влияния особенностей личности на поведение в юридически значимых обстоятельствах.

Таким образом, очевидна недооценка роли психологического познания при исследовании инцидентов особой тяжести содеянного. В целевые задачи деятельности патопсихолога, принимающего участие в психиатрических исследованиях, входит выявление дифреренциальнодиагностических критериев патопсихологических симптомокомплексных расстройств в познавательной и личностной сферах испытуемого. Субъектом исследования патопсихолога является личность, психическое состояние которого может быть деструктивным. Патопсихолог определяет степень и качество выраженности деструктивного состояния.

К исследовательским задачам судебного психолога относится совокупность параметров (включая и патопсихологические факторы), связанных: как с изучением конкретных обстоятельств криминального инцидента, так и с изучением конкретных психических процессов, свойств, состояний и механизмов психической деятельности человека, проявление которых обусловлено этими криминальными обстоятельствами, что имеет важное значение для установления истины по уголовному делу.

Учитывая нынешнее состояния теории, методологии и методических возможностей практического определения личности в рамках психологической экспертизы, индивидуально-психологические особенности могут быть разграничены по:

- диагностике личности и характере ее направленности;

- оценке влияния личностного фактора на поведение исследуемого в ситуации интересующей следователя или судебного исполнителя.

В соответствии с рассматриваемым Постановлением Пленума Верховного суда (п. 12) «при квалификации умышленного убийства по пункту «ж» ч. 2 ст. 97 УК РУз. необходимо установить, что умыслом виновного охватывалось совершение убийства с особой жестокостью. При этом следует иметь в виду, что понятие особой жестокости связывается как со способом убийства, так и с другими обстоятельствами, свидетельствующими о проявлении виновным особой жестокости. .....Множественность телесных повреждений при убийстве может быть оценена как проявление особой жестокости, только если виновный действовал с прямым умыслом на причинение потерпевшему особых страданий и мучений» [3].

По нашим наблюдениям, практика проведения психологических экспертиз в Республике Узбекистан, а именно касательно вопроса умысла в психиатрической компетенции (прямого ли, косвенного) не исследуется, а значит - не учитываются параметры жестокости, парадоксальность проявления которой должна анализироваться и диагностироваться судебными психологами. Проявления жестокости в психиатрическом освидетельствовании соотносятся либо с «невменяемостью» (при совокупности признаков болезненного состояния), либо с «вменяемостью», детерминация которой не имеет обоснований.

В понимании исследования преступлений, связанных с особенностями проявлений эмоциональных состояний, входящих в компетенцию психологических исследований (фрустрация, стресс, фризиологический афрфект), фрактор «парадоксальной жестокости» обусловлен 
множественностью нанесённых жертве ранений различной локализации. Обращаясь вновь к нашему накопленному практическому опыту отметим, что данное обстоятельство в большинстве случаев для следствия и судебных инстанций не является востребованным параметром, поскольку рассматривается как отягчающее ответственность подследственного (подсудимого).

Согласно Постановлению Пленума Верховного суда от 24.09.2004г., (п. п. 2.,3.) «следует иметь в виду, что умышленное убийство может быть совершено как с прямым, так и с косвенным умыслом. При совершении умышленного убийства виновный действует с умыслом на лишение жизни потерпевшего, предвидит общественно опасные последствия, желает (прямой умысел) либо сознательно допускает (косвенный умысел) наступление смерти. В связи с этим следует устанавливать, действовал ли виновный с намерением лишить жизни потерпевшего, желал ли он наступления смерти, какие обстоятельства помешали наступлению желаемого результата». Согласно УК РУз., ст. ст. 98, 106 определяются соответственно как «Умышленное убийство в состоянии сильного душевного волнения», так и «Причинение умышленного тяжкого или средней тяжести повреждения в состоянии сильного душевного волнения» [5].

Следует признать, что понятие «умышленное деяние» по данным статьям нуждается в разъяснениях, поскольку в комментариях УК РУз. по ст. 98. п. 2. отмечено, что «физиологический афрфект - это внезапно возникшее сильное душевное волнение, представляющее собой кратковременную, но бурно протекающую эмоциональную реакцию; яркая, кратковременная вспышка, и в то же время - чрезвычайно сильное бурное переживание; гнев, переходящий в ярость; страх, доходящий до ужаса; тоска, достигающая отчаяния, в результате чего, виновный в значительной мере утрачивает возможность контроля над своими действиями и способность руководить ими» [3].

С учетом вышеизложенного, следует отметить, что «в значительной мере утрата способности лица контролировать свои действия» в ситуациях криминального деликта (неправомерного поведения) не совпадает с понятием «умышленного» деяния, связанного с убийством в состоянии фризиологического афрфекта. «Умышленное деяние» предполагает осознание умысла (мотива), целеполагания, как предусмотрено в ст. 97 УК РУз.

Афрфект - это сложное, чрезвычайное, парадоксальное, кризисное состояние души человека, требующее особой, экспертной научно-психологической оценки.

Согласно комментариям УК РУз «основанием квалификации убийства как совершенного в состоянии сильного душевного волнения являются два момента. Во-первых, противоправное насилие, тяжкое оскорбление или иные противоправные действия потерпевшего. Во-вторых, нахождение виновного лица в момент убийства в состоянии сильного душевного волнения» [2].

По мнению М.Х. Рустамбаева, при «совершении убийства в состоянии сильного душевного волнения «умысел» виновного может быть как прямым, так и косвенным, но обязательно он должен быть афрфектированным (внезапно возникшим). «Мотивы убийства могут быть различными, но, как правило, это месть потерпевшему за его противоправное или аморальное поведение» [6].

Б.В. Сидоров, анализируя мотивы преступления, совершённые в состоянии афрфекта, приходит к выводу, что не месть лежит в основе противоправного поведения, а обида (как переживание), причиняющая человеку огорчение, оскорбление, душевную боль. «Мотив в фрорме мести», по мнению автора, исключает фризиологический аффрект, так как действия виновного перестают при этом носить «извинительный» характер [7]. 
Между тем, О.Д. Ситковская утверждает, что «афрфект - как мотив преступления, характеризуемого скоротечностью, осознаётся субъектом лишь в свернутом виде. Конечно, он в свою очередь детерминирован длящимся, либо внезапно возникшим, но интенсивным межличностным конфрликтом. Но в момент афрфектированного преступления доминирующим побуждением является именно афрфект, а вызвавшие его побуждения выступают лишь в качестве сомотивов» [8].

Совершенно очевидно, что возникновение аффекта по какому-либо мотиву невозможно, так как мотив - это понятие осознанности и целенаправленности будущих действий индивида. Можно сказать, что противоправные действия в состоянии аффеекта возникают на фоне сужения сознания и дезорганизации поведения, при одновременном ощущении индивидом субъективной безвыходности из сложившейся ситуации. В мировой научной психологии сложились определённые представления о фризиологическом аффректе и определённых градациях его протекания с учётом личностных особенностей. В частности указывается, что противоправные действия, совершённые в состоянии аффректа, чужды и противоречат позициям и установкам в поведении испытуемых в их обыденной жизни.

В данном случае, понятие «умышленности» деяния (осознание умысла) не совпадает с представлениями о «внезапности» возникновения криминальной реакции, исключающей способность контроля действий в обстоятельствах, превышающих пределы «адаптационных возможностей». На наш взгляд, в данном случае выявляются противоречия, обусловленные несоответствием понятий «умысла» и ограниченных способностей контроля и прогноза действий, совершаемых в кульминационной фразе криминального инцидента.

В комментариях УК РУз ст. 98 «Умышленное убийство в состоянии сильного душевного волнения» законодатель отождествляет данное состояния с состоянием физиологического аффректа. По мнению М.Х. Рустамбаева «ответственность по ст. 98 УК исключается, если смерть потерпевшего находилась в причинно-следственной связи с действиями виновного, совершенными не в афрфекте, а в ином эмоциональном состоянии (стресс, фрустрация и т.д.)» [6].

На мой взгляд, с учетом методологической позиции, к понятию «сильного душевного волнения» следует относить и такие эмоциональные состояния как: «эмоциональное возбуждение», «стресс», «фррутрация». Данная позиция обусловлена тем обстоятельством, что рассматриваемые состояния отличаются от афрфекта, но имеют общие с афректом признаки, связанные с ограничением способности контроля (сужением сознания) и прогноза действий человека в момент совершения криминального инцидента.

Поскольку предметом настоящего исследования являются особенности проявления эмоциональных состояний («эмоциональное возбуждение», «стресс» и «фррустрация»), а в совокупность признаков, диагностирующих отмеченные состояния входят резкое ограничение контроля и прогноза своих действий, то представления об умышленности поведения, включающим понятие «умысла», также, по крайней мере, требуют разъяснений.

Приведу пример из нашей экспертной практики. Так, была проведена судебно-психологическая экспертиза в отношении 22 летнего Х.Ж., обвиняемого по ст.97 ч.1 УК РУ, у уоторого на момент совершения инкриминируемого деяния было диагностировано состояние «эмоционального возбуждения», которое не достигало выраженности проявлений физиологического аффекта, однако оказало существенное влияние на его деятельность, ограничив его осознанность и произвольность. Обоснованием для определения «эмоционального возбуждения» являлась совокупность диагностируемых признаков, характерных для данного состояния, а именно: наличие 
афрфектогенной ситуации с предшествующим моментом накопления негативных переживаний, субъективная внезапность наступившей реакцией, достаточная диффреренцированность воспоминания о случившемся и недостаточная выраженность кульминационной фазы. Криминальный деликт возник в обстоятельствах, спровоцированных противоправным (агрессивным) поведением потерпевшего. Данные признаки, обуславливающие феноменологию «эмоционального возбуждения», предполагают как значительное сужение поля восприятия, таки и значительное снижение возможности контроля и прогноза поведения испытуемого в криминальном деликте. Однако, в судебном расследовании выводы судебно-психологической экспертизы учтены не были и подсудимый был приговорен к 15 годам лишения свободы.

Таким образом, следует отметить, что законодатель должен учитывать криминальные деликты, которые были совершены человеком при ограничении возможностей контролировать свои действия и прогнозировать их последствия. При вынесении приговора судебные инстанции руководствуются УК РУз, а также комментариями к данному законодательству, которые, на наш взгляд, необходимо учитывать в криминальных преступлениях по «человеческому фрактору» эмоционального состояния, включающего в себя не только «аффеективные» деликты, но и деликты, обусловленные эмоциональным возбуждением, стрессом и фррустрацией.

\section{Список литературы}

1. Брусиловский Е.А. Судебно-психологическая экспертиза. Предмет, методика, пределы. - Харьков, 1929. - С. 18.

2. Комментарий к Уголовному кодексу Республики Узбекистан. Основная часть. - Тошкент, 2016. - C. 38.

3. Постановлению Пленума Верховного суда от 24.09.2004 года N 13 «О судебной практике по делам об умышленном убийстве». www. lex.uz

4. Кудрявцев И.А. Судебно психолого-психиатрическая экспертиза. - Москва, 1988. - С.132.

5. Ўзбекистон Республикаси Жиноят кодекси. - Тошкент, 2007. - С. 225, 228.

6. Рустамбаев М.Х. Курс уголовного права Республики Узбекистан. Особенная часть. Том 3: Преступления против личности. Преступления против мира и безопасности. Учебник для ВУЗов. - Тошкент, 2008. - С. 83-91.

7. Сидоров Б.В. Афрфект. Его уголовно-правовое и криминологическое значение. - Казань, 1978. - С. 37-38.

8. Ситковская О.Д. Судебно психологическая экспертиза аффекта // Методическое пособие. Москва, 1983. - С. 60.

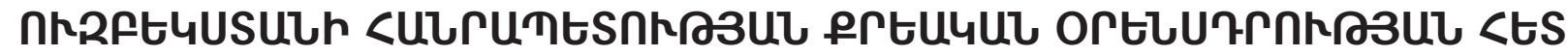

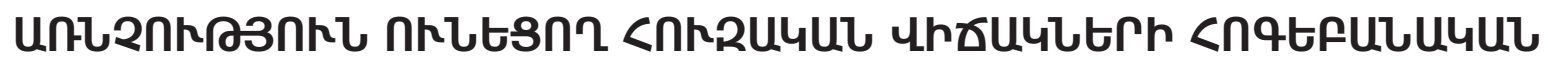

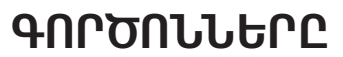

\section{Uwhứnınnyu tu.S.}

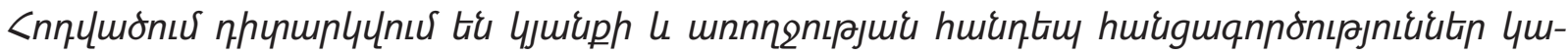

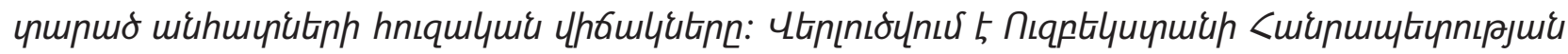

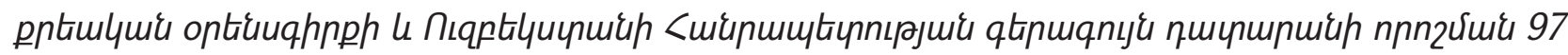

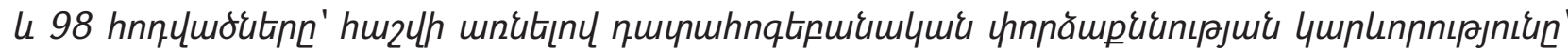




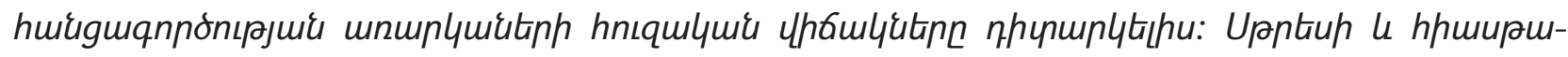

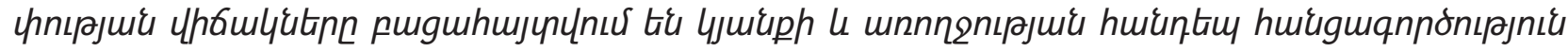

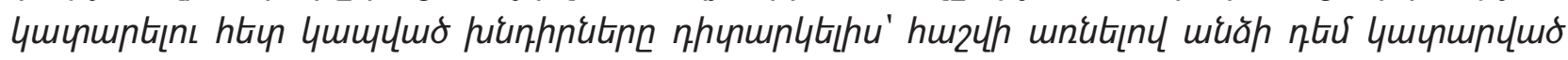

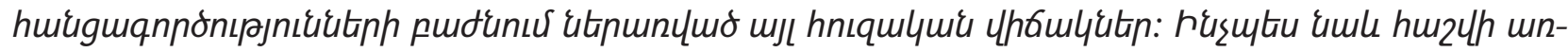

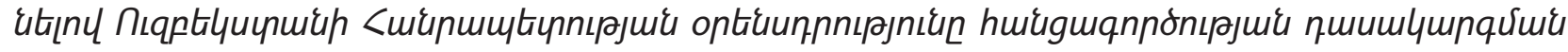

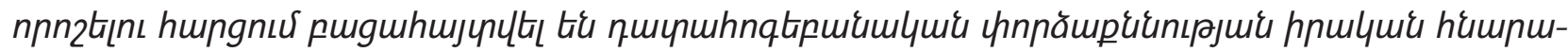
unnnıpлnıultinn:

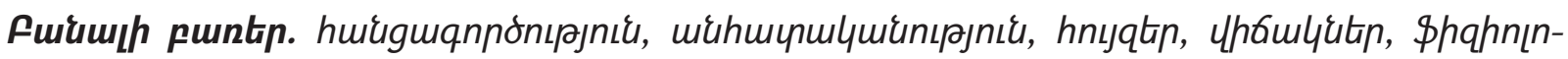

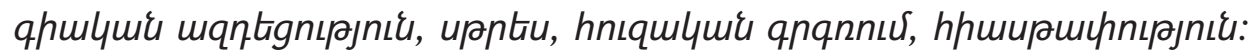

\section{PSYCHOLOGICAL FACTORS OF EMOTIONAL STATES RELATED TO THE CRIMINAL LEGISLATION OF THE REPUBLIC OF UZBEKISTAN}

\section{Makhmudova $K$.}

The article examines the emotional states of individuals who have committed crimes against life and health. The article analyzes Articles 97,98 the Criminal Code of the Republic of Uzbekistan and the Resolution of the Supreme Court of the Republic of Uzbekistan, taking into account the importance of forensic psychological examination, when considering the emotional states of the subjects of the crime. The states of stress and frustration are revealed when considering issues related to the commission of a crime against life and health, taking into account other emotional states included in the section of crimes committed against the person. It also reveals the actual possibilities of forensic psychological examination in deciding the issue of qualifying a crime, taking into account the legislation of the Republic of Uzbekistan.

Key words: crime, personality, emotion, states, physiological affect, stress, emotional arousal, frustration.

Статья поступила: 30.03.2021

Принята к печати: 10.04.2021 